\title{
Research of structure and properties of boride hardening coatings
}

\author{
Dmitriev Sergey, Malikov Vladimir, Sagalakov \\ Anatoly, Grigorev Alexey \\ Faculty of physics and technology \\ Altai State University, ASU \\ Barnaul, Russia \\ dmitrsf@gmail.com
}

\author{
Ishkov Alexey \\ Faculty of physics and technology \\ Altai State Agrarian University, ASAU \\ Barnaul, Russia \\ mirotnas@gmail.com
}

\begin{abstract}
Strengthening of parts and units of machines, increased reliability and longer service life are an important task of modern aerospace industry. As promising materials for protective-strengthening coatings, matrix composites based on ternary system Fe-B-FenB are offered. The aim of the research was to apply boride coatings on the surface of steel parts. Relevance is conditioned by the necessity to harden the surface of steel used in high-load conditions. Samples of coatings on 65 G grade steel, applied by HFC-heating, were obtained. Research of samples with different coatings studied using the metallurgical microscope was carried out. Research data on samples with different coatings applied by means of an eddy current measuring system were obtained and conclusion on electrical conductivity distribution along the sample surface depending on flux quantitative content during boriding was made.
\end{abstract}

Keywords- boride coatings; diffusion boriding; eddy-current transducer; HFC-heating; introduced voltage; RMS deviation

\section{INTRODUCTION}

Creation of promising disposable and reusable hypersonic airborne devices in aerospace industry requires complex solutions of a range of problems, one of which is research and development of high-temperature heat-protective coatings.

Relevance of this research is based on the fact that airborne vehicles, when in a long-duration flight in the atmosphere, are exposed to considerable aerodynamic heating under impact of air pressure. Materials of airborne vehicles have to maintain high durability, temperature resistance, minimal linear shrinkage.

A rise of efficiency effectiveness of heat-protective materials is assured with use of coatings that raise temperature resistance and mechanical durability of materials. In virtue of theoretical and experimental research, basic requirements for a hardening coating composition were created: working temperature $-1650^{\circ} \mathrm{C}$; a $20-30 \%$ raise of compressive strength of gradient fibrous material with no more than $3 \%$ change of its thermophysical properties $[1,2]$.

The process of "classic" diffusion boriding is a rather common method of steel and steel parts case-hardening. During boriding, two-phase saturable surface is most often obtained, it consists of mixed borides $\mathrm{FeB}, \mathrm{Fe}_{2} \mathrm{~B}$ and a transition zone - solid boron solution, as well as other elements of steel in $\alpha-F e$.

Boron atoms have relatively small size and high mobility; therefore, they can easily diffuse into ferrous alloys, forming $\mathrm{FeB}$ and $\mathrm{Fe}_{2} \mathrm{~B}$ intermetallics [3]. According to the boron-iron phase diagram, a maximum amount of boron that can form a single-phase $\mathrm{Fe}_{2} \mathrm{~B}$ is 33.5 at.\% [4].

Boron is one of the elements that can generate unique properties in the steel surface. The use of hard layer (such as boride) to improve surface properties is a method for protecting substrate from environmental effects. The boride layers have high hardness, low porosity, high corrosion resistance, and adhesive wear resistance [5].

The thermo-chemical boriding process of steel allows FeB and $\mathrm{Fe} 2 \mathrm{~B}$ phases to be obtained. Generation of these layers can improve the surface hardness and wear resistance of equipments and components for tribological applications. By controlling the boron potential in the steel surface, both singlelayer (only the $\mathrm{Fe}_{2} \mathrm{~B}$ phase) or multilayers ( $\mathrm{FeB}-\mathrm{Fe}_{2} \mathrm{~B}$ phases) can be produced [6]. The presence of the $\mathrm{FeB}$ phase

in the layers leads to the brittleness of layers and high stress intensity at $\mathrm{FeB}-\mathrm{Fe}_{2} \mathrm{~B}$ interface [7].

After the "classic" boriding, the coating microstructure, most often, is coalescent at the bottom of boride needles, that form a coating layer. Resulting internal tensile stresses in the borated coating significantly reduce their plasticity, therefore peeling and chipping of such a hardening coating occur, until its complete destruction, at relatively small bending, shock or compressive stresses and especially reversed loads and vibrations.

All of the aforesaid restrains application of the isothermal boriding process for a wide use when hardening parts surfaces made of steel in agricultural machinery industry.

Boriding is a thermochemical surface treatment, in which boron is diffused into and combined with the substrate material forming a single or double-phase metal boride layer on the surface. Unlike many other surface treatments, hard boride layers can be developed on most alloys and metals by boron diffusion. The boriding of ferrous materials causes the formation of either a single layer $(\mathrm{Fe} 2 \mathrm{~B})$ or double-layer 
$\left(\mathrm{FeB} / \mathrm{Fe}_{2} \mathrm{~B}\right)$ with a definite composition. The thickness of the layer formed (which is known as the case depth) influences the mechanical and chemical behaviors of the borided steels that depends on the boriding temperature, the treatment time and the boron potential that surrounds the sample surface [8]. When the treatment time and temperature are increased, the $\mathrm{FeB}$ regions become much deeper, and they grow from compact and oriented $\mathrm{Fe}_{2} \mathrm{~B}$ crystals. The phases grow preferentially in the (002) plane, increasing the mechanical stress over the $\mathrm{FeB} / \mathrm{Fe}_{2} \mathrm{~B}$ interface because of the significant differences between the expansion coefficients of both phases in the range from 473 to $873 \mathrm{~K}$ [9].

The surface hardness of the boride layers is usually measured by traditional techniques such as the Knoop and Vickers microhardness. However, as a result of its wide acceptance for exploring the mechanical behavior of elastic plastic materials such as ceramics. The nanoindentation technique has also been used to measure different mechanical properties under monotonic loading and unloading, in which the data are usually processed by the manner proposed by Oliver and Pharr [10]. Some devices also enable continuous stiffness measurement (so-called CSM mode), where a small harmonic signal (amplitude of several nmor a fraction of amN) is added to the monotonously increasing basic load. The harmonic contact stiffness is measured continuously, and makes it possible to determine properties during loading from "zero" to the maximum force. However, the CSM mode is especially suitable for materials with a time-dependent response such as plastics or biomaterials $[11,12]$.

In recent years, Culha et al. [13] employed ultramicrohardness tests to estimate the mechanical properties of FeB layers, such as the dynamic hardness and the Young's modulus in AISI 1020 and 1040 borided steels.

The steels were exposed to different experimental conditions during the boriding process. The load-dependant elastic modulus and the dynamic hardness values of the FeB layer were within the range of 125-397 GPa and 775-1381 $\mathrm{HV}$, respectively. The validity of the Young's modulus values proposed in [14] was verified taking into account that the indentation depth should not exceed $10-25 \%$ of the boride layer thickness, avoiding the effect of the steel properties in the elastic values of the FeB layer. In addition, finite element modeling was applied to simulate the yield strength of the FeB layer on a low-alloy steel substrate; the resultant values ranged from 5 to $7 \mathrm{GPa}$ [14].

The mechanical properties such as fracture toughness, compressive residual stresses, and the indentation size effect (ISE) were also evaluated in the tips of the needles of the Fe2B layer using the Berkovich nanoindentation technique [15]; the results showed an apparent hardness of approximately $14 \mathrm{GPa}$ with a fracture toughness between 2.4 and 2.7 $\mathrm{MPa}$, and the compressive residual stresses were between 351 and $471 \mathrm{MP}$

In case of boriding by HFC-heating, the speed of coating formation increases hugely more due to an increase of heating rate. If special fluxes are used there is no need to create a protective atmosphere, since the boriding time does not exceed several minutes. Besides HFC-heating allows one to reduce time of high temperatures effect on the base material, as well as to combine easily the boriding process with subsequent heat treatment. In the future, little time for boriding carried out by HFC-heating may promote the use of this boriding method in flow production lines, in mass production, and production of large quantities of hardened parts per shift.

Preliminary experiments carried out by us showed the principal possibility of boride coatings formation on steel parts surface during HFC-heating. During preliminary experiments, it was ascertained and confirmed that when the heating rate was increased, the rate of reaction and consequently the formation of coating increased hugely more in comparison with isothermal case-hardening in the furnace, and it was ascertained that it was necessary to use borate fluxes, for example P-0.66 flux, to obtain high-quality, indistinguishable coatings.

\section{MATERIALS AND MEASUREMENT PROCEDURE}

As promising materials for protective-strengthening coatings, the authors offered matrix composites based on the ternary system $\mathrm{Fe}-\mathrm{B}-\mathrm{Fe}_{\mathrm{n}} \mathrm{B}$, formed directly on the surface of the reinforcing parts, during its boriding in conditions of induction heating of the charge of the original composition and the various functional fillers.

Coating of the ternary system $\mathrm{Fe}-\mathrm{B}-\mathrm{Fe}_{\mathrm{n}} \mathrm{B}$ is formed by induction heating on the surface of the reinforcing parts when passing exothermic topochemical reaction between iron steel and boron the charge. The reaction captures the surface layer of the base-material, and the reaction products form with it a single whole and are characterized by smooth changing of the chemical composition of the transition at the interface basecoat which determines their high adhesion strength and durability, special properties [16, 17].

Coating samples were obtained for $65 \mathrm{G}$ grade steel made of compositions of boron carbide and amorphous boron under conditions of high-frequency heating to research boriding processes performed together with HFC-heating of the surface of structural and alloy steels of main grades used in an agricultural machinery industry, and the effect of carbon and alloying elements in steel, physical, physical and mechanical properties and wear resistance of boride coatings.

Boride coatings of $65 \mathrm{G}$ steel during simultaneous SHS process and $\mathrm{HFC}$-heating were obtained from a modified mixture of a $2 \mathrm{Al}+\mathrm{B}_{2} \mathrm{O}_{3}$ composition containing 20 and $30 \%$ of P-0.66 flux. Temperature of boriding process in all cases was $950-1250^{\circ} \mathrm{C}$; saturation time was $40-180 \mathrm{sec}$.

The higher composition of $\mathrm{Al}$ in $\mathrm{FeB}-\mathrm{Al}$ coating results in thicker coating. An interdiffusion layer, which is composed of intermetallic phases, is formed in FeB-50 at.\% Al coating after heat treatment [18].

The compositions were applied to the prepared (cleaned) surface of $50 * 100 * 5 \mathrm{~mm}$ of $65 \mathrm{G}$ steel plates when daubing, and after drying they were subject to HFC-heating according to the same mode: first, before the initiation of the SHS process, and then, at reduced generator power by $25 \%$ within 60-80 sec. 
Templates and samples for metallographic examination were prepared from the obtained samples. To prepare microsections, a manual cutting machine, a sharpening machine and a manual grinding-and-polishing machine were used.

To determine samples structure, the surface of prepared microsections was treated with $4 \%$ nitric acid solution in ethyl alcohol within 5-7 seconds. The main objects of study in the work were selected steel $65 \mathrm{G}$, wear-resistant boride coatings, which were investigated by electron microscopy (Philips SEM - 515) and the eddy-current measurement system.

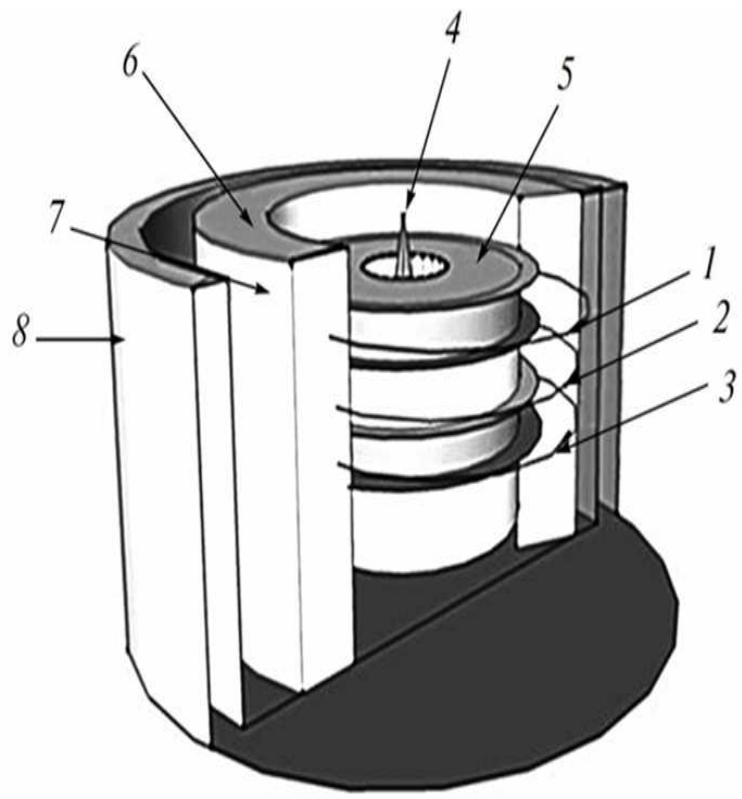

Fig. 1. Scheme of eddy current transducer

Subminiature ECT $[19,20]$ is designed for experimental local studies of the thickness of various coatings and to determine the effect of various coatings on the output signal value. The developed subminiature ECT represents a core wrapped with the following windings: energizing, measuring and compensation. ECT consists of a core wrapped with the energizing, measuring and compensation windings. Both the windings and the core are impregnated with a compound. They are enclosed in a washer of corundum. This equates to increase the mechanical stability of the transducer.

To test different conductive materials, a developed transducer is used, which is connected to a personal computer via a sound card that is used as a generator and as a signal transducer. The signal thus is sent directly to the energizing winding.

The software is able to control the quantity of a signal applied to the energizing winding and also allows to read the voltage values from the measuring winding, which, taking into account the calibration, are converted into conductivity values.
The developed software allows measuring the thickness of conductive and dielectric non-ferromagnetic coatings and conductive materials

ECT winding coils consist of a copper wire with the thickness of $5 \mu \mathrm{m}$. The core is made of ferrite 2000 NM3 with an initial magnetic permittivity value of 2000 and has a pyramidic shape. Characteristics of the developed transducer make it possible to achieve high localization of the control, namely, to localize the field within $2500 \mu \mathrm{m}^{2}$. The developed system provides a significant depth of penetration of the field into the prototype system up to values of $\sim 5 \mathrm{~mm}$ (at frequencies of $500 \mathrm{~Hz}$.)

The eddy-current transducer (Figure 1) is a transformer with measuring (1), exciting (2), and compensation (3) windings and magnetic circuit 4 , which is located inside cylindrical platform 5 with tracks that are cut on the external side for windings. The platform is impregnated with a compound 6 at a temperature of $200^{\circ} \mathrm{C}$ to prevent the disintegration of the windings when ferrite screen 7 , which is intended for the localization of the electromagnetic field on the tested object, is put in place. From the outside, the transducer is contained in a corundum washer 8, which protects the core 4 from contacting the tested object.

The software coded in $\mathrm{C}++$ for Windows allows controlling the signal on the energizing winding and receiving the signal from the measuring winding. With the help of the software it is possible to effectively control the signal, which is applied directly to the energizing winding. Also with this software it is possible to receive a signal directly from the measuring winding. The impressed voltage can be controlled using a special mixer built into the Windows. With the help of this mixer, the frequency and amplitude parameters of the generator sinusoidal signal are set. In turn, the sound card makes it possible to extend the signal bandwidth, which is applied directly to the energizing winding.

\section{RESULTS AND DISCUSSION}

Photos of samples were taken by means of OLYMPUS GX51 inverted metallographic microscope after etching of microsections, and response value of VDDS-5 eddy-current gage system was obtained as it moved above the sample surface.

Research results for the structure of coating obtained by SHS process during HFC-heating of modified mixtures containing 20 and $30 \%$ P-0.66 flux for $65 \mathrm{G}$ steel are shown in Figures 2-9.

As it can be seen in Figures 2-4, the structure of coating formed is one of the typical ones found earlier in boride coatings obtained from mixtures based on amorphous boron, the thickness of the resulting coating is 230-250 $\mu \mathrm{m}$. Signal amplitude of eddy current transducer (Figure 5) when scanning along the surface of sample under research varies significantly (RMS deviation - $12.6 \mathrm{mV}$ ), this allows one to conclude that the obtained coating is unevenly conductive. 


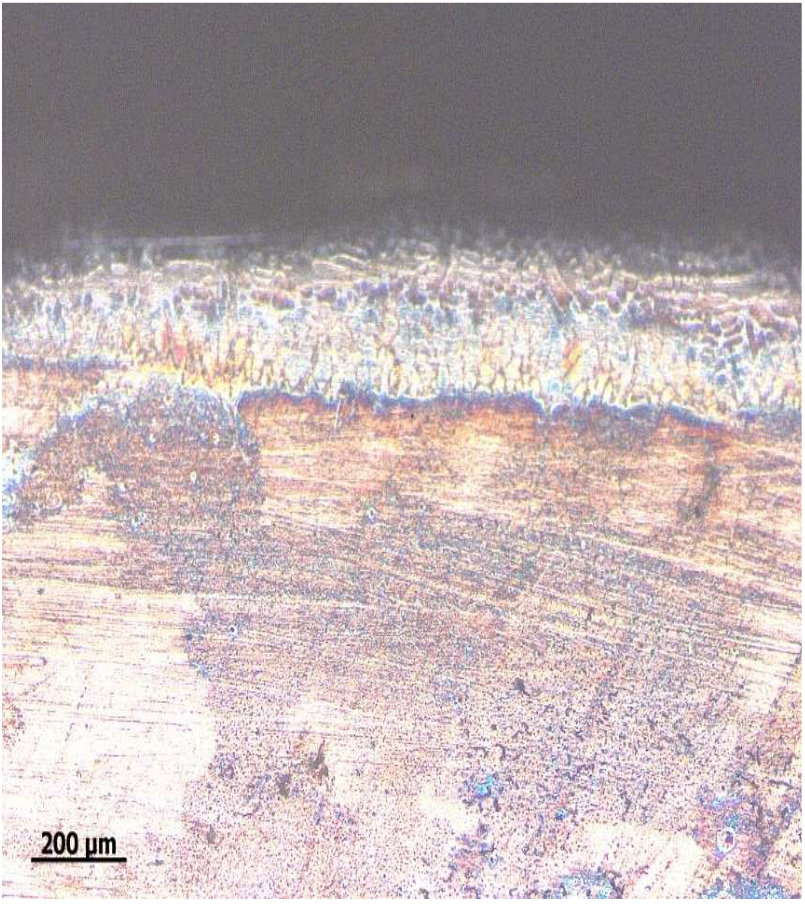

Fig. 2. Microstructure of coating received from modified mixture with $20 \%$ of P-0.66 flux (enlargement $\times 100)$

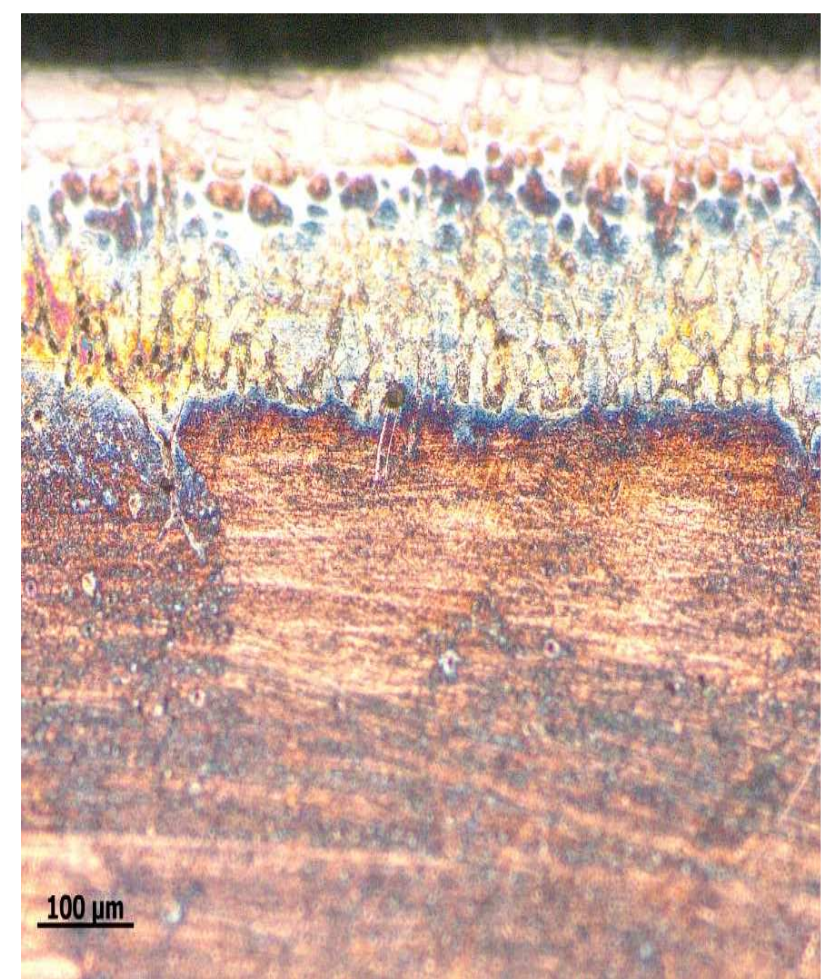

Fig. 3. Microstructure of coating received from modified mixture with $20 \%$ of P-0.66 flux (enlargement $\times 200$ )

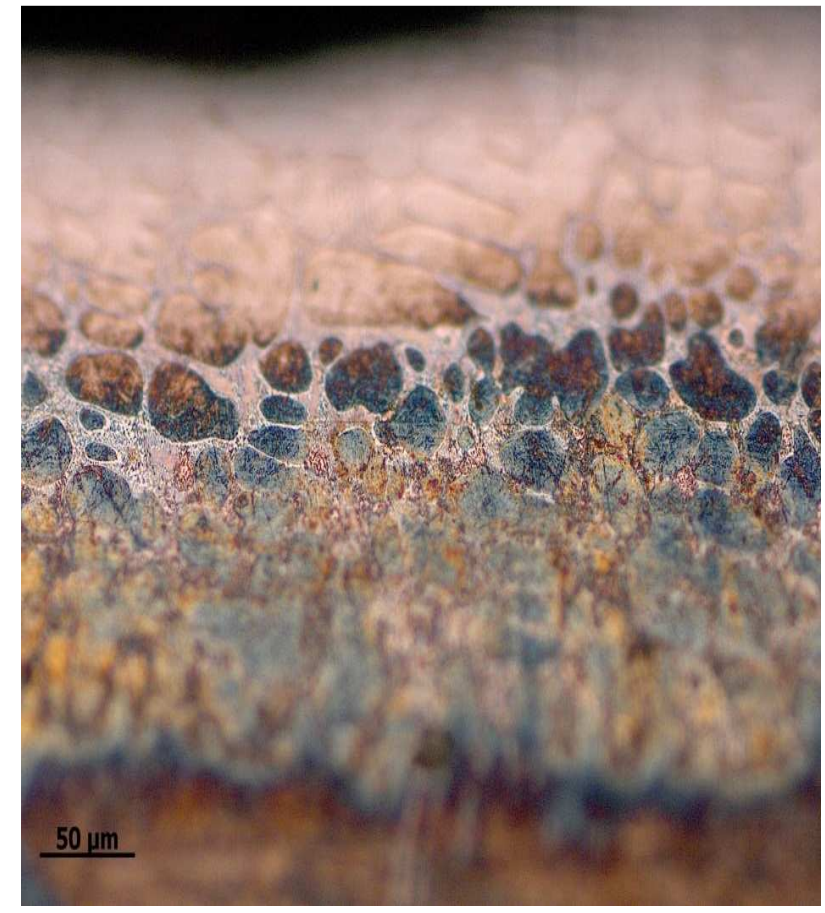

Fig. 4. Microstructure of coating received from modified mixture with $20 \%$ of P-0.66 flux (enlargement $\times 500$ )

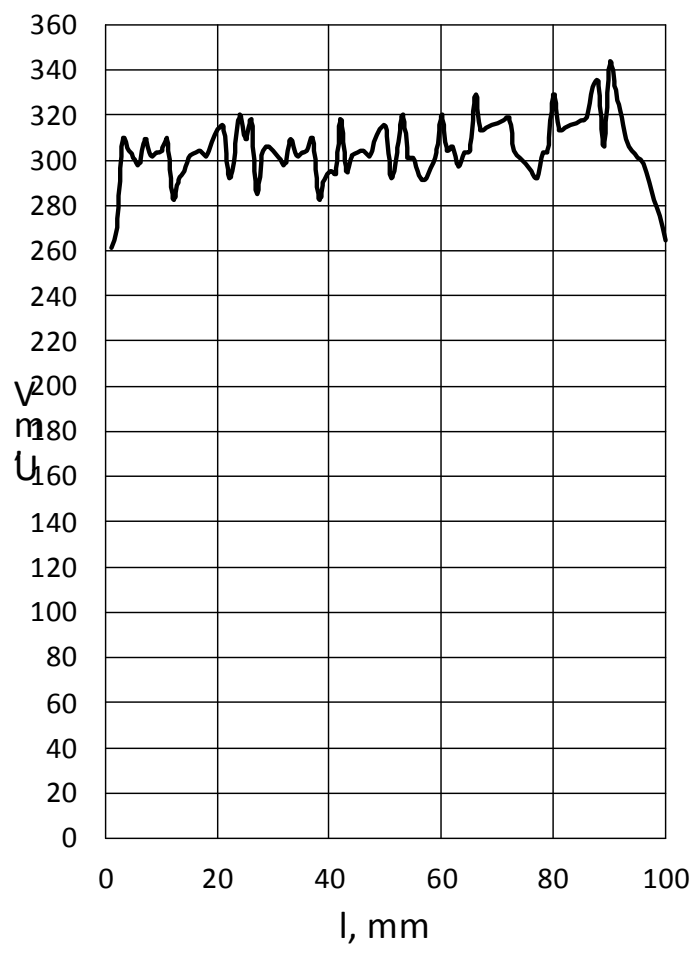

Fig. 5. Signal of eddy-current transducer VS location of sensor above object that is under research 
Figures 6-8 show that if the content of P-0.66 flux increases, a similar structure of boride coating is formed in the modified mixture, having a marked boundary with a base metal, but its thickness is smaller and amounts to $170-190$ $\mu \mathrm{m}$. Signal amplitude of an eddy current transducer (Figure 9) when scanning along the surface of the sample under research changes significantly less than in the standard mixture (RMS deviation of $4.6 \mathrm{mV}$ ). This allows one to conclude that there is much less change in electrical conductivity of the obtained coating.

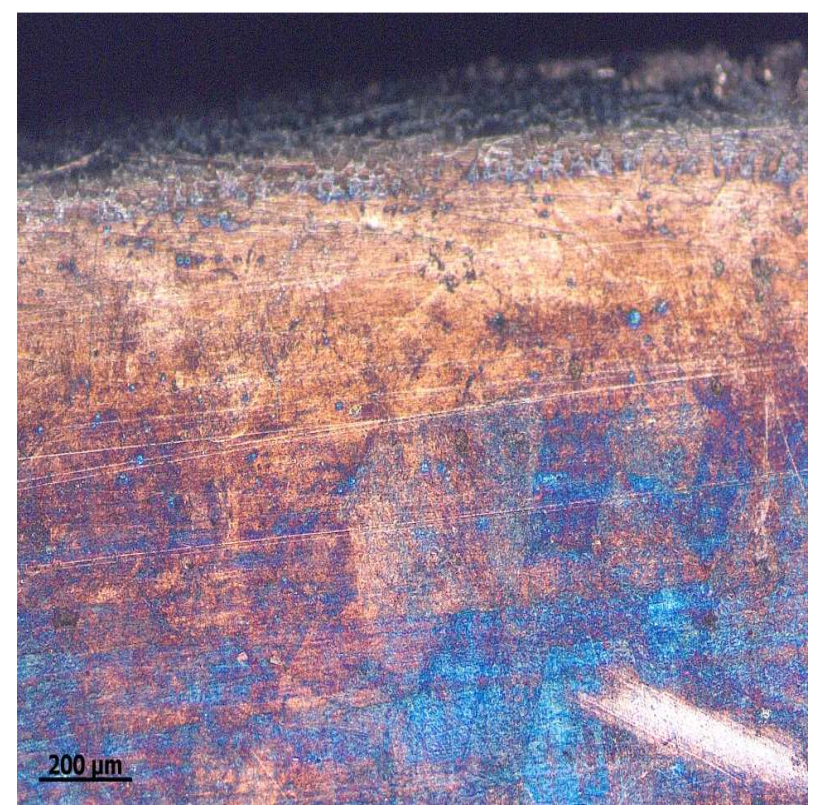

Fig. 6. Microstructure of coating received from modified mixture with $30 \%$ of P-0.66 flux (enlargement $\times 100$ )

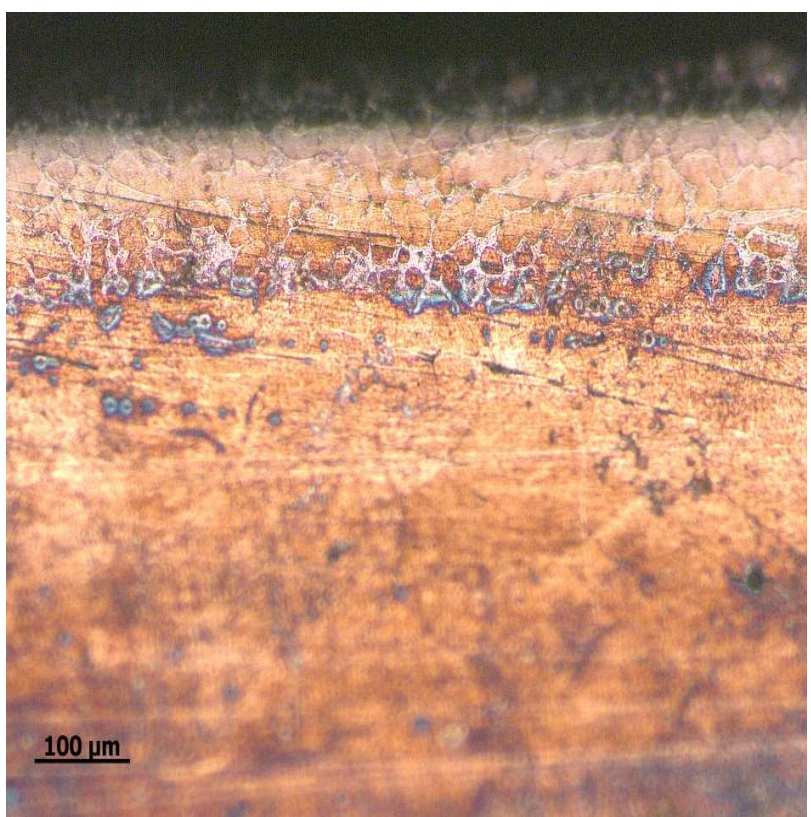

Fig. 7. Microstructure of coating received from modified mixture with $30 \%$ of P-0.66 flux (enlargement $\times 200$ )

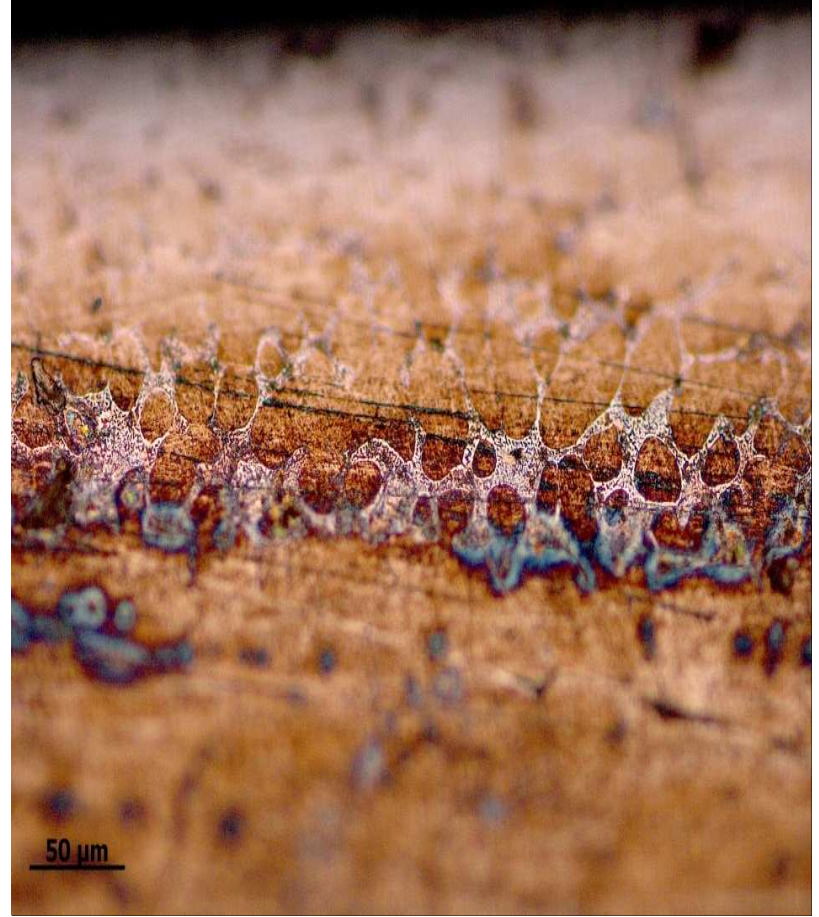

Fig. 8. Microstructure of coating received from modified mixture with $30 \%$ of P-0.66 flux (enlargement $\times 500$ )

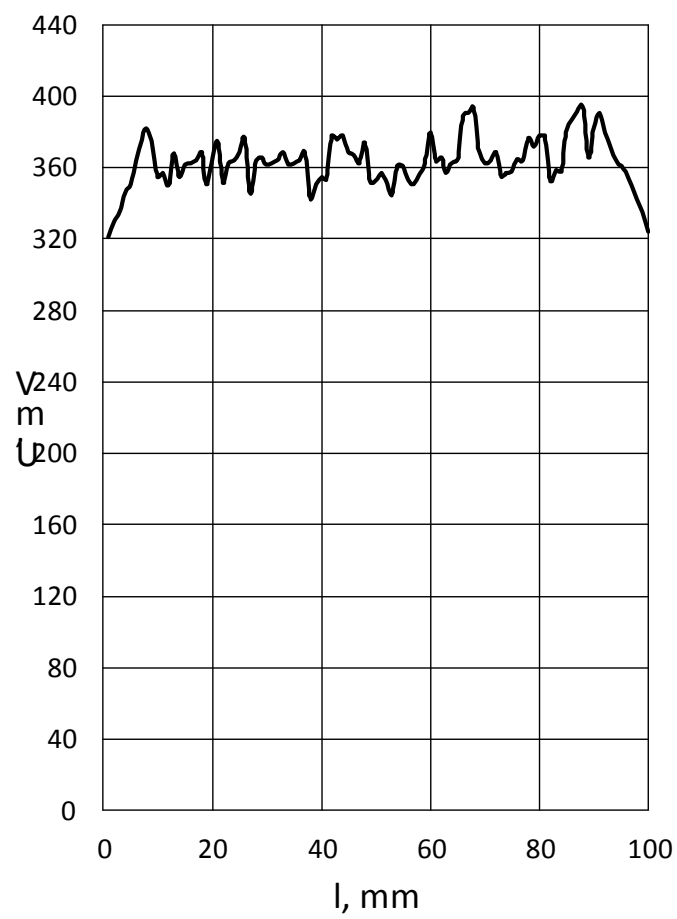

Fig. 9. Signal of eddy-current transducer VS location of sensor above object that is under research 


\section{CONCLUSIONS}

Boride coatings obtained in both cases are two-phase composite materials. The darker closed rounded areas are free of boron non-stoichiometric carbide phases of FexC composition (where $\mathrm{x}=1,2-2,5$ ), the microhardness of which is $650-680 \mathrm{HV}$, the lighter separating net of their interlayer is Fe-B-C ledeburite-like iron-boride ternary eutectic, which microhardness reaches 850-920 HV. The hardness of the base metal is $400-450 \mathrm{HV}$. The difference in electrical conductivity fluctuations of the obtained coatings is determined.

\section{References}

[1] S. Solntsev, V. Mironova, "Effect of ceramic coatings on the sound absorbtion of heat-shield materials", Glass and Ceram, vol. 69(5), pp. 200-203, May 2012.

[2] S. Solntsev, V. Rozenenkova, "Ceramic coatings for the protection of high-strength steel during heat treatment", Aviation materials and technology, vol. 4, pp. 3-5, April 2011.

[3] M. Nunney, Light and Heavy Vehicle Technology, Michigan: Newnes, 1992.

[4] T. Garrett, K. Newton, W. Steeds, The Motor Vehicle, Butterworth:Heinemann, 2000, pp. 125-126

[5] J. Larson, L. Jenkins, "Engine Valves-Design and Material Evolution", Eng. Gas Turbines Power, vol. 109, pp. 355-361, February 1987.

[6] F. Dittrich, Composite Carbide Flame Spray Material, Patent US3419415, 1968.

[7] S. Narasimhan, S. Caird Titanium nitride coated valve and method for making, Patent US5441235, 1995.

[8] I. Campos-Silva, M. Ortiz-Domínguez, "Kinetics and boron diffusion in the $\mathrm{FeB} / \mathrm{Fe} 2 \mathrm{~B}$ layers formed at the surface of borided high-alloy steel", J. Mater. Eng. Perform, vol. 21, pp. 1714-1723, August 2012.

[9] M. Rile, "Causes of crack formation in borided layers of steel", Metalloved. Term. Obrab. Met, vol. 10, pp. 20-23, May 1974.

[10] W. Oliver, G. Pharr, "An improved technique for determining hardness and elastic modulus using load and displacement sensing indentation experiments", J. Mater. Res, vol. 7, pp. 1564-1583, January 2011.

[11] J. Menčík, "Characterization of viscoclastie-plactic properties of solid polymers by instrumented indentation", Pol. Test,, vol. 30(1), pp. 101109, February 2011.

[12] J. Menčík, "Determenation of mechanical properties by instrumened indentation", Meccanica, vol. 42, pp.19-29, April 2007.

[13] O. Culha, M. Toparli, S. Sahin, T. Aksoy, "Characterization and determination of $\mathrm{Fe}_{\mathrm{x}} \mathrm{B}$ layers' mechanical properties", J. Mater. Process. Technol, vol. 206, pp. 231-239, March 2008

[14] O. Culha, M. Toparli, "Estimation of FeB layer's yield strength by comparison of finite element modeling with experimental data", Adv. Eng. Softw, vol. 40(11), pp. 1140-1147, November 2009.

[15] I. Campos-Silva, E. Hernández-Sánchez, G. Rodríguez-Castro, "Indentation size effect on the $\mathrm{Fe}_{2} \mathrm{~B} /$ substrate interface", Surf. Coat. Technol, vol. 206, pp. 1816-1823, December 2011.

[16] V. Yankauskas, E. Katinas, E. Skirkus. "The method of hardening soil rippers by surfacing and technical-economic assessment", J. Frict. Wear, vol. 35(4), pp. 270-277, July 2014.

[17] A. Shitov, A. Vedeneev, "The influence of various factors on the wear of the working organs of tillers", Remont, Vosstanov., Modern, vol. 7, pp. 30, July 2002.

[18] R. Sundawa, D. Aryanto, A. Wismogroho, T. Sudiro, "Microstructure and phase composition of Fe-B-Al coatings on low carbon steel prepared by using mechanical alloying technique", J. Phys.: Conf. Ser, vol. 817,April 2017.

[19] S. Dmitriev, V. Malikov, A. Sagalakov, A. Katasonov, "Eddy-current measuring system for analysis of alloy defects and weld seams" Rus. Eng. Res, 36(8), pp. 626-629, September 2015.
[20] S. Dmitriev, A. Ishkov, V. Malikov, A. Sagalakov, "Scanning the Welded Seams of Titanium Alloys by Using Subminiature Eddy Current Transducers", Mat. Sci. For., vol. 906, 147-152, September 2017. 